\title{
REVOLUCIÓN Y EVOLUCIÓN TEATRAL EN EL PUERTO RICO DE LOS SETENTA Y LOS OCHENTA
}

\author{
POR \\ SANTOS TORRES ROSADO \\ Indiana University of Pennsylvania
}

Durante las décadas de los setentay los ochenta, el arte puertorriqueño de la representación experimenta un proceso de innovación y ruptura en relación al teatro que le precede. Si los dramaturgos anteriores a este período (Manuel Méndez Ballester, Francisco Arriví y René Marqués, entre otros) reflejan en sus obras la preocupación por la definición y conservación de la puertorriqueñidad, los entonces nuevos dramaturgos se enfrentan a unas realidades socio-políticas que les exigen nuevos métodos de representación de la realidad.

La Guerra de Vietnam, los movimientos independentistas de la Universidad de Puerto Rico, la lucha por la autonomía universitaria, en adición al ambiente represivo, constituyen el contexto que enmarca el surgimiento de lo que Roberto Ramos-Perea denomina la Nueva Dramaturgia Puertorriqueña (NDP). ${ }^{1}$

Para Ramos-Perea existen dos ciclos en el desarrollo de la NDP. El primero cubre de 1966 hasta el 1975 y se caracteriza por la ruptura que crea el teatro popular y colectivo en relación al teatro convencional (13). Respondiendo a la condiciones históricas del primer ciclo, las obras producidas se convierten en literatura de emergencia dirigida a la masa, por lo que adoptan el didactismo del teatro obrero de las décadas del 10 y el 20 . La creación se caracteriza por el trabajo colectivo de investigación en los lugares donde acontecen los sucesos representados. Un elemento innovador es la participación activa de la audiencia en "la acción como personaje y hablante activo de la trama (48)". Ramos-Perea indica que "Los inicios del primer ciclo establecen un compromiso ideológico que llega a través del teatro popular (43). Surge, no obstante, un radical cambio en tanto el compromiso "se transforma de un enfoque planfletario a un enfoque didáctico que, cumpliendo con el compromiso de enseñar la realidad, hace preguntas sobre ella". (34)

\footnotetext{
'Santos Torres-Rosado falleció el 9 de mayo de 1993. Este artículo lo redactó durante su última enfermedad.

1 Roberto Ramos-Perea. Perspectiva de la nueva dramaturgia puertorriqueña 1. Puerto Rico: Cuadernos del Ateneo, Serie de teatro. Todas las citas remiten a esta fuente. Las páginas citadas se darán de forma parentética en el texto mismo. El libro de Ramos-Perea es uno de los estudios más completos en relación al período histórico mencionado. La importancia de dicho estudio la constituye el hecho de que Ramos-Perea no es sólo estudioso del teatro puertorriquefio, sino partícipe del proceso. Este trabajo queda en deuda con Roberto Ramos-Perea y su libro.
} 
La producción de este primer ciclo surge de manera ecléctica al incorporar el didactismo del teatro obrero y la participación de los espectadores con el compromiso ideológico del teatro popular. El resultado es una obra donde el planfleto político ha sido substituido por el cuestionamiento de la situación social, lo que por resultado tiene la conversión del espectador de ente pasivo a ente activo.

Básicamente el quehacer teatral, no convencional, del primer ciclo recae en cinco importantes grupos de trabajo. El primero de ellos es el grupo El Tajo del Alacrán creado en 1966. Aunque comienza montando obras en teatros convencionales es, de acuerdo con José L. Ramos Escobar, "el que abrió nuevamente las puertas a un teatro eminentemente popular en contenido y público" (17). ${ }^{2}$

Establece Ramos Escobar que, de acuerdo con Lydia Milagros González, fundadora de El Tajo, el grupo se proponía:

hacer un tipo de teatro que planteara los problemas actuales en que nos debatíamos como pueblo, un teatro de tono jocoso, que hiciera críticas como las hace el pueblo, en relajo, pero hablando en serio, en fin un teatro para el pueblo (17-8).

Entre los postulados teóricos de El Tajo se destaca la necesidad de un compromiso vital con la realidad interpretada en las obras, ya que "Para hacer teatro popular no basta con comprender al pueblo, hay que sentir con el pueblo" (Ramos Escobar, 18). Entre 1970 y 1971, El Tajo del Alacrán representa, en diferentes comunidades, La tumba del jibaro, La venta del bacalao rebelde, La huelga, La despropiación, y iQué importa un muerto más!

Hacia 1969 surge, de los pasillos de la Universidad de Puerto Rico, (UPR) el grupo Anamú (la yerba que el chivo no mastica). Dicho grupo, comprometido con la lucha estudiantil, monta la obra El archivo en el teatro de la U.P.R. En 1972 el grupo se mueve a la calle (más de 200 representaciones) con la obra Pipo Subway no sabe reír de Jaime Carrero. La pieza (re)presenta la situación de un niño puertorriqueño en un barrio de Nueva York. Durante el mismo año escenifican en la calle la obra Aqui es donde el zapato aprietay la lucha empieza. En 1973 llevan al pueblo Ya los perros no se amarran con longaniza de Jorge Rodríguezy José Luis Ramos, pieza que trata sobre el alto costo de la vida en la Isla. Se añaden a la nómina de ese mismo año, El chou de la hora cero como reacción a la propuesta de construir un superpuesto en la costa oeste de Puerto Rico, y Bahía sucia, bahía negra escrita en colaboración directa con los pescadores afectados por el derramamiento de petróleo del barco griego Zoe Kolocotronis en el suroeste de la Isla.

Del grupo Anamú surgen el Teatro de Guerrillas (1969) en afiliación a la Federación de Universitarios Pro Independencia, y Moriviví (1972). Al cabo de tres años los grupos Anamú y Moriviví vuelven a unirse para formar el Colectivo Nacional de Teatro (1975). La gran aportación de Anamú y Moriviví al teatro popular se encuentra en el método de creación colectiva. Los textos:

\footnotetext{
${ }^{2}$ José L. Ramos Escobar. "Génesis y desarrollo del teatro popular en Puerto Rico". Intermedio de Puerto Rico 3-4, vol. I, (año I), 12-21. Todas las citas remiten a esta fuente. Se dará el número de página de manera parentética en el texto mismo.
} 
se escribían entre todos los miembros del grupo luego de una investigación sobre el tema. El texto se producía mediante discusiones e improvisaciones, y jamás alcanzaba una forma definitiva pues se continuaba modificando a medida que las reacciones del público ... le indicaban al grupo la necesidad de añadir, suprimir o cambiar alguna escena. Esto le confería a las obras un gran dinamismo y una gran actualidad ... [que] permitía incorporar a la obra sucesos acaecidos el mismo día (Ramos Escobar 19).

El segundo ciclo de la NDP se gesta entre 1975 y 1978 alcanzando su ápice en la actual dramaturgia (Ramos-Perea 13). Dos importantes aspectos determinan el final desarrollo de la NDP. El primero es el derecho al uso de las grandes salas que las instituciones gubernamentales le negaron por mucho tiempo. El segundo es el alcanzar el reconocimiento del valor literario de sus obras, valor que constantemente fue atacado por los dramaturgos canónicos. El regreso a las grandes salas convencionales no implica ruptura con las innovaciones logradas por el primer ciclo, sino su ulterior desarrollo. Entre las más importantes aportaciones de la NDP se destacan la transformación del lenguaje, las técnicas dramáticas de escena y los mensajes (temas).

Uno de los aspectos más importantes ocurre en el lenguaje. La NDP substituye el lenguaje altisonante de los dramaturgos establecidos por uno que conforma la expresión directa y sincera del lenguaje popular. Para Ramos-Perea,

Mucha de la NDP escribe como se habla. ... Un teatro que logra una total identificación con los procesos de un pueblo no puede cerrarse a lo que lo une a él: su lenguaje. (51)

Esta revolución lingüística rescata:

africanismos, anglicismos, modismos caribeños o franceses y más aún, la jerga de la juventud o la del lumpen [como] fuente rica y necesaria en la proyección de la realidad que se pretende traducir. (51)

El lenguaje dramático, tanto verbal como escénico, se convierte en posibilidad de comunicación directa con el pueblo y no en mero juego intelectual. Como lo demuestra el más reciente estudio Memory and Modernity: Popular Culture in Latin America de William Rowe y Vivian Schelling, ${ }^{3}$ en nuestra literatura el elemento popular ha sido una constante. No obstante, tanto la NDP como la actual literatura latinoamericana han revolucionado la funcionalidad de dicho uso. El tradicional recurso de lo popular como elemento folklórico de ambientación es superado otorgándosele valor estructural en la creación de las obras.

En relación a los recursos y estructura del montaje escénico la NDP, dada su experiencia con el teatro popular, abole los grandes montajes. Los efectos especiales como la luminotécnica y recursos auditivos se disminuyen o eliminan para trabajar el mensaje a través de la palabra, de la acción. De esta manera se diluye la posible distracción de los espectadores ante los grandes montajes escénicos. A esta reducción escenográfica se añade la incorporación de elementos técnicos que permiten la trasmisión clara del mensaje. Ramos-Perea los enumera de la siguiente manera:

\footnotetext{
${ }^{3}$ William Rowe and Vivian Schelling. Memory and Modernity: Popular Culture in Latin America. Londres: Verso, 1991.
} 
... el uso de distintas expresiones plásticas como la pintura y la escultura y la inclusión definitiva de la música como elemento unificador. La influencia del cine en la continuidad de las escenas, la trasposición de planos, el contrapunto, el movimiento corporal ya no como símbolo, sino como expresión autónoma y viva. (36)

Uno de los mayores aciertos de la NDP ha sido la ruptura y revolución en relación al mensaje (tema) que presenta en sus obras. Como se mencionara anteriormente, la preocupación por la identidad puertorriqueña es superada por el estudio de lo que en la actualidad somos. Este nuevo enfoque permite la traducción literaria de los actuales problemas socio-políticos que aquejan al país. Dicha apertura permite la representación de mensajes considerados tabú o censurables por la crítica hegemónica. Se destacan, entre otros, la drogadicción, la homosexualidad (toda la producción de Abniél Marat), el lesbianismo, la represión policíaca, la corrupción gubernamental, el desahucio y la violencia contra el puertorriqueño pobre tanto del caserío como del arrabal, la desintegración de la familia tradicional como efecto de la transculturación, los todavía vigentes problemas de la Universidad de Puerto Rico y la invasión de extranjeros a la Isla (Ramos-Perea 33).

En el área del teatro infantil se cuentan grupos como El Mago Ambulatorio y Alondra. Entre otras obras infantiles se destacan: Nadorcito (1982) y Brujilla (1983) de Rosita Marrero. Ángel Amaro desarrolla su personaje Pelusín en obras como: Pelusin y sus amigos (1981), La orquídea y Pelusin (1981), Pelusin y los payasos (1982) y La noche mágica de Pelusin (1982).

La NDP a través de nuevas técnicas tanto literarias como teatrales, la innovación del teatro popular, el rescate de la lengua del pueblo y la ruptura con los temas canónicos se ha constituido en un corpus que ha revolucionado el convencional teatro puertorriqueño. A pesar de una existencia de más de veinte años el quehacer teatral no es un producto final; la aparición de nuevos dramaturgos y la experimentación creativa aportan nuevos elementos que señalan a una continua evolución. Como medio de asegurar el intercambio de ideas y la preservación del proceso, la NDP cuenta con La revista InterMEDIO de Puerto Rico (1985), ${ }^{4}$ la Sociedad Nacional de Autores Dramáticos (SONAD), fundada en 1984, y el Archivo Nacional de Teatro Puertorriqueño (1988).

\section{MíNIMA GUIA DE LA NDP 5}

Algarín, Miguel. Olu Clemente (1973).

Amaro Sánchez, Ángel. Chía (1965), Port People (1976), El Gólgota de hierro (1976), La vida rosa (1977), Pelusín y sus amigos, La noche mágica de Pelusin (1982), Si tu madre quiere un rey (1983), Ermelinda (1984).

Anamú. Ya los perros no se amarran con longaniza (1973), El chou de la hora cero (1973), Bahia sucia, bahía negra (1973).

\footnotetext{
${ }^{4}$ InterMEDIO de Puerto Rico: Primera Revista de Teatro Puertorriqueño, bajo el auspicio de la Fundación René Marqués (Urb. Villa Nevárez, Calle 1 \#1101, Río Piedras, Puerto Rico 00927).

${ }^{5}$ La presente no es una lista completa de obras o autores pertenecientes a la NDP, sino una pequeña muestra de lo producido. El único criterio usado es la alfabetización de autores.
} 
Bezares, Fernando. Los altos del garage (1973).

Blanco, Miguel Concepción. Vamos pa' New York (1981).

Canales, Carlos Juan. Corrupción (1984), Maria del Rosario, La casa de los inmortales (1985).

Carrero, Jaime. La muñeca de crepé envuelta en celofán (1965), Flag Inside (1966), El caballo de Ward (1971), Pipo Subway no sabe reir (1971), Noo Jork (1972), La caja de caudales FM (1976), Lucky Seven (1979), Frenesi (1983), Miedo al sol (1984).

Ceide, Abelardo. Lupita se va del rancho (1974), La cebolla (1976), Frankest ELA (1976), Alba de Puerto Rico (1981).

Colectivo Nacional de Teatro. A puño cerrado (1972).

Conde, Ramón "Moncho". Sali del caserio, Juan el obrero (1981), El viejo San Juan (1975), El cable (1984), Macario (1984).

Córdova, Getsy. Responso por un amor triste (1982), Cuentas viejas (1984), La gran convención (1983).

Cruz Barreto, Roberto. Podría ser esta noche (1977).

Cuevas, Clara. El rompecabezas (1970), Los buitres del alma (1971), La casa de los espejos (1971).

Escalera, Carlos. Sin principio sin fin (1981).

Expósito, José. Trilogía de la desesperación (1981), Círculo de sangre (1983).

Ferrari, Carlos. Puerto Rico Fuá (1973).

González, Coqui. En boca de mujer (1978), Me importo yo (1973).

González, Juan. Doce paredes negras (1971), La plena murió en Mayagüez (1976).

González, Lydia Milagros. La tumba del jibaro (1968), La venta del bacalao rebelde (1971) La muerte en Vietnam (1971), Gloria la bolitera (1972).

González, Lylel. Culebra USA (1973).

Jusino Campos, Edgardo. Un domingo en familia.

Laviera, Tato. Olu Clemente (1973).

Marat, Abniel. Nocturno en el sexo de los unicornios (1981), Dios en el playgirl de noviembre (1984). Nota: Abniel Marat es un seudónimo de Víctor Abniel Morales.

Marichal, Teresa. Las horas de los dioses nocturnos (1978), Pista de circo, Xion, El parque más grande de la ciudad (1980), Prohibido hablar, Caos, Yo, una prisionera de guerra, Cassandra (1981), Cortaron a Elena (1982), La tragedia del amor Frankestein (1983), Amor de medianoche, Paseo al atardecer, Mermelada para todos (1984).

Márquez, José "Papo". Esquizofrenia Puertorricensis (1975), La terapia (1980), Amordio (1981).

Marrero, Rosita. Nadorcito (1982), Brujilla (1983).

Martínez Tolentino, Jaime. La imagen del otro (1980), El miedo (1983).

Modesti, Mirelsa. El bosque encantado (1984).

Molina, Samuel. Tiempo para la ira (1981).

Morales, Jacobo. Muchas gracias por las flores (1973), Cinco sueños en blanco y negro (1975), Aquella, la otra, éste y aquél (1978), Una campana en la niebla (1979).

Morales, Aleyda "Kookie". Diálogos de la burocracia (1976), En caso de que hayas considerado la alternativa de que el verde se encuentra en el más allá(1979), Estampas de mujer (1983), Esos seres extraños (1984). 
Morales, Víctor Abniel. Psicosis paranoide (1981), Nocturno en el sexo de los unicornios (1981), Dios enel playgirl de noviembre (1982), La historia del loco que se volvió cuerdo (1984).

Moreno, Zora. El Afroantillano (1975), Dime que yo te diré (1975), Con machete en mano (1976), Coquí coriundo vira el mundo(1981), Maria está tostá(1982), Elmito de Beatriz (1984).

Muratti, José. Testigos, ¿Verdad, darling? (1983).

Ortiz, Roberto "Pachi". El tumbe (1980), La linea (1983).

Ortiz, Rafael. Agapito's Watergate (1974), Cara a cara ante el pay (1972), Yo maté a la burocracia (1976).

Pérez Garay, Flora. El gran pinche (1979), El ay el amor y el interés (1984).

Pietri, Pedro. Masses are Asses (?).

Piñeiro, Miguel. Short Eyes (1973).

Pizarro, Pablo. A pesar de la lluvia (1976).

Quiles, Rosario. El juego de la trampa (1978), El censo (1980).

Ramírez, Agustina. Puertas adentro, El idolo (1975).

Ramírez Córdoba, Antonio. Collage para teatro total (1973), Vacío tambor (1984).

Ramos, José Antonio. Papo Impala está quitao (1984).

Ramos-Perea, Roberto. El marrón menopáusico (1976), Eran de carne quemada (1977), El sueño vicioso (1979), Fetora, Revolución en el infierno, Revolución en el purgatorio o Módulo 104, Los 200 No (1982), Cueva de ladrones o Revolución en el paraíso (1983), Crimen y castigo (1984), Camándula (1985).

Rivas, Joey. Arcos de sangre (1984).

Rodríguez, Walter. La descomposición de César Sánchez, Línea viva(1973), Lapersecución de Octavio Pérez (1975).

Roja, Rueda. La pulga.

Rosario Quiles, Luis Antonio. El juicio de Victor Campolo (1971), La movida de Victor Campolo (1973).

Ruiz Escobar, Jaime. Treintainuna (1973), 31 (1974), Pensarás que todo lo que has visto puede ser cierto (1978), El funeral de la esperanza (1984).

Santaliz, Pedro. El cemi en el Palacio de Jarlem (1969), Chebelto Cofresi (1970), Cadencia en el País de las Maravillas (1973), Sentimiento en la vida de Hemoglobina Valdés, La niña de la lengua diaria, Culantrillo (1972), Serenito se cayó frente a Padín (1976), El teatro personal de Meaíto Laracuente (1981), El Castillo Interior de Medea Camuñas (1984).

Santiago, Ubaldo. Noche en un clamor sordo (1980), Un día en la plaza (1981).

Torres Alonso, Juan. La ventana (1973).

El Tajo del Alacrán. La vida nueva (1969), Te conozco bacalao (1971), Gloria la Bolitera (1972).

Torres Nadal, Luis. El asesinato de una mariposa, La cena gentil (1973), La víspera del día después (1974), La santa noche del sábado (1975), El problema de papá(1983), Maten a Borges (1984) 